Eur. J. Clin. Chem. Clin. Biochem.

Vol. 32, 1994, pp. 341-347

CC 1994 Walter de Gruyter \& Co.

Berlin · New York

\title{
Lipoprotein(a) Concentrations in Cord and Capillary Blood from Newborns and in Serum from In-Patient Children, Adolescents and Adults
}

\author{
By Marianne Schumacher ${ }^{1}$, Andrea Keßler ${ }^{1}$, Arnhild Meier ${ }^{2}, S$. Weigert ${ }^{3}$ and W. G. Wood ${ }^{1}$
}

1 Institut für Klinische Laboratoriumsdiagnostik

2 Klinik für Gynäkologie und Frauenheilkunde

3 Kinderklinik

Klinikum der Hansestadt Stralsund, Stralsund, Germany

(Received December 2, 1993/January 26, 1994)

Summary: Investigations have been made upon the distribution of lipoprotein(a) concentrations in cord and capillary blood from newborns and in serum from in-patient children and adults. Full-term neonates $(n=123)$, children aged 1 month to 16 years $(n=331)$ and adults aged between 17 and 88 years $(n=252)$ of age were included in the study.

Lipoprotein(a) was determined using an immunoluminometric assay and a single lot of reagents. The assay had an effective measuring range of $1-800 \mathrm{mg} / \mathrm{l}$.

Lipoprotein(a) could be measured either in cord or capillary blood in the majority of cases. Problems arose in isolated cases, in each of which there was a large concentration difference in lipoprotein(a) between mother and child. The correlation data was: $\mathrm{r}=0.897, \mathrm{n}=37, \log$ (capillary blood) $=0.874 \log$ (cord blood) +0.165 . The median lipoprotein(a) concentrations in cord and capillary blood were 13.9 and $10.2 \mathrm{mg} / \mathrm{l}$ respectively.

Median lipoprotein(a) concentrations increased from birth up until the 6th decade (159 mg/l), decreasing to $95 \mathrm{mg} / \mathrm{l}$ during the 9th decade of life. In mature newborns, the median lipoprotein(a) concentrations correlated with gestational age.

The distribution of lipoprotein(a) concentrations in serum is skewed throughout life, the ratio mean/median being 2.07 at birth, 2.71 in children and 2.72 in adults. The percentage of children with lipoprotein(a) concentrations above $250 \mathrm{mg} / \mathrm{l}$ was 23.0 (male) and 23.8 (female). The corresponding figures for adults was 38.2 for males and 28.2 for females respectively. In the group of newborns 27.7 percent had concentrations above $25 \mathrm{mg} / \mathrm{l}$.

There was no significant difference between median lipoprotein(a) concentrations after delivery in 80 healthy mothers aged $17-35$ years $(92.5 \mathrm{mg} / \mathrm{l})$ and 51 age matched in-patients $(104 \mathrm{mg} / \mathrm{l})$. Adult males had significantly higher median serum lipoprotein(a) concentrations than adult females $(p<0.05$, males $144 \mathrm{mg} / \mathrm{l}$, females $89 \mathrm{mg} / \mathrm{l})$.

\section{Introduction}

Although several studies have been reported on the lipid and lipoprotein concentrations of newborns and children $(1-6)$, relatively few studies have been reported on the establishment of reference ranges for lipoprotein(a) in these groups $(7-11)$. Since lipoprotein(a) levels for newborns have been determined both in blood spots $(8$,
10) and in serum or plasma $(9,11)$, we have to take account of different concentration ranges and decision levels. It is to be expected that lipoprotein(a) levels in whole blood are approximately half those in serum or plasma, and that they are related to the haematocrit. Contradictory reports on the serum or plasma levels of lipoprotein(a) during pregnancy and postpartum have 
been published $(12,13)$; the use of different methodology may account for the differences found (12). At presence there is little or no treatment for diminishing lipoprotein(a) levels in blood (with the exception of the HELP apheresis) but there is a need for the early recognition of children at risk of developing atherosclerotic disease due to abnormally high levels of lipoprotein(a). Even for adults, the recommended upper limits of lipoprotein(a) (14) have been accepted without sufficient investigation or statistical analysis.

This study was implemented to study the concentrations of lipoprotein(a) in newborns, children, adolescents and adults, using a single method of detection (15). Capillary and cord blood concentrations of lipoprotein(a) in newborns were compared, in order to establish age-linked reference ranges, and to establish files on newborns with elevated lipoprotein(a), so that they can be observed more frequently and be treated as soon as this becomes possible. As lipoprotein(a) is accepted as an independent risk factor, for atherosclerosis, its serum concentration can be used to assess the general risk for early cardiovascular disease (8), together with the other more generally accepted lipid and lipoprotein analytes such as total cholesterol, triacylglycerols and LDL-cholesterol (16).

One advantage of the present study is that all results were obtained using a single lot of reagents, including standard material. This is of importance, because there are no accepted reference materials for lipoprotein(a), and different methods give rise to different results (15), so that comparison of results is often difficult.

\section{Materials and Methods}

\section{Subjects studied}

Newborns $(\mathrm{n}=123)$ in the gynaecological clinic were examined for lipoprotein(a) levels using cord blood samples, and where possible, capillary blood. As the determination of lipoprotein(a) required only $10 \mu \mathrm{l}$ serum, no problems were encountered. At the same time, the lipoprotein(a) concentration of the mother was also measured in serum. If the father was present at the birth, he was asked whether he would allow blood to be taken for lipoprotein(a) determination.

In addition, lipoprotein(a) was determined in serum from 331 inpatient children from the paediatric wards, using samples taken for routine laboratory tests. None of the children had been admitted because of a known lipid disorder.

Lipoprotein(a) concentrations were also measured in the serum of 252 non-selected patients from all wards of the hospital to cover the age range $17-88$ years.

Methods of analysis

Lipoprotein(a) was determined using an immunoluminometric assay as already described and published in this journal (15). As the samples must be diluted 1:10 before assay, using a sample size of $10 \mu \mathrm{l}$, the method was suitable for samples from neonates and children.
In certain selected cases with elevated lipoprotein(a), serum was subjected to lipid electrophoresis and analysed for triacylglycerols and cholesterol. Results from these cases are not presented here.

\section{Statistics}

As it is known that lipoprotein(a) is not normally distributed, nonparametric tests were used. The median was used as the point of central tendency, the dispersion being given in terms of relevant percentiles. Correlations were made using the Spearman rank correlation procedure.

\section{Results}

\section{Newborns}

Although 123 newborns were included in the study, it was not possible to obtain cord blood and capillary blood from each baby, so that only 37 newborns could be included in this group.

Figure 1 shows the lipoprotein(a) concentrations in cord blood plotted against those in capillary blood. As can be seen, the correlation was good, with several exceptions, where the cord blood concentration lay between the maternal and newborn value. The most extreme cases were: maternal serum $27.6 \mathrm{mg} / \mathrm{l}$, cord blood $103 \mathrm{mg} / \mathrm{l}$, newborn serum $267 \mathrm{mg} / \mathrm{l}$ and maternal serum $150 \mathrm{mg} / \mathrm{l}$; cord blood $68.5 \mathrm{mg} / \mathrm{l}$, newborn serum $26.7 \mathrm{mg} / \mathrm{l}$. Combinations such as: maternal serum $1400 \mathrm{mg} / \mathrm{l}$, newborn serum $14.9 \mathrm{mg} / \mathrm{l}$, i. e. mother high, baby low, were not uncommon. These values are given to show that the measured lipoprotein(a) concentration of cord blood is not always a reliable index of the serum concentrations. Whenever the concentrations in cord and capillary blood were discrepant, there was also a large difference between maternal and offspring lipoprotein(a) levels.

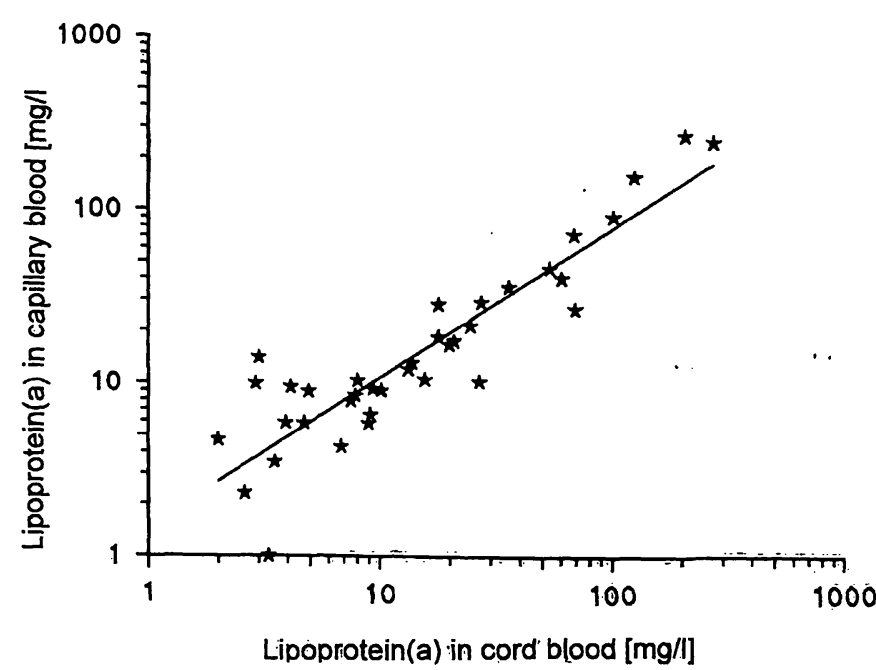

Fig. 1 Comparison of lipoprotein(a) concentrations in cord blood and capillary blood in 37 newborns. The logarithmic scale was chosen because the data show a non-Gaussian distribution. The correlation coefficient $r=0.897$; the slope of the regressive line is: $\log y=0.874(\log x)+0.165 \ldots$ 
The median value of the lipoprotein(a) concentrations in newborns lay well below those found in children older than 6 months, and in adults. There was a slight, but insignificant correlation between lipoprotein(a) concentrations at birth and the gestational age, more prematurely born babies having lower values on average, as seen in figure 2.

Figure $3 a$ shows the distribution of lipoprotein(a) values in the cord blood of newborns. The median value for lipoprotein(a) in cord blood was $13.9 \mathrm{mg} / 1$ (range $<1-354 \mathrm{mg} / \mathrm{l}$ ) and in capillary blood $10.2 \mathrm{mg} / \mathrm{l}$ (range $<1-336 \mathrm{mg} / \mathrm{l})$. The values were logarithmically distributed. In one case, where the mother had a lipoprotein(a) value of $1150 \mathrm{mg} / \mathrm{l}$, the lipoprotein(a) values in the baby rose from $125 \mathrm{mg} / \mathrm{l}$ at birth to 169,264 and $344 \mathrm{mg} / \mathrm{l}$ on days 2, 6 and 9 postpartum. During the study, two women gave birth to heterozygotic twins, in each case a boy and a girl. In the one case, the lipoprotein(a) levels were 3.2 and $3.4 \mathrm{mg} / 1$. The other twins presented with metabolic problems and were admitted to hospital at 6 months. The lipoprotein(a) levels were found to be 684 and $712 \mathrm{mg} / \mathrm{l}$. This demonstrates the non sex-linked codominant inheritance of lipoprotein(a) attributes $(17,18)$.

\section{Children and adolescents (age 1 month to 16 years)}

Figure 2 shows the distribution of median lipoprotein(a) concentrations in serum with age. It is clear that although lipoprotein(a) levels are genetically codominantly determined, the peak values in serum do not appear to be reached before the end of the sixth decade of

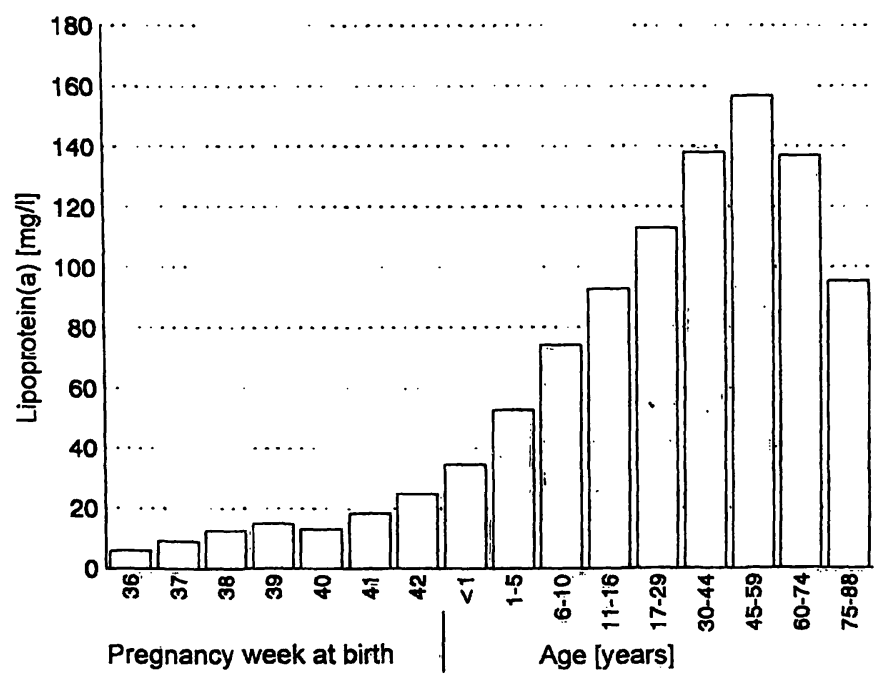

Fig. 2 Distribution of median lipoprotein(a) values in 706 persons from birth up until the 88th year of life. The abscissa is divided into two portions, the left section shows the pregnancy week in which the child was born; the right section the age groups of the children, adolescents and adults. life, the median values sinking thereafter. Figure $3 \mathrm{~b}$ shows the individual values from 331 children sorted according to age. Both parents of one child (age 6 years, with lipoprotein(a) concentrations above $2.3 \mathrm{~g} / \mathrm{l}$ ) had elevated levels (mother $945 \mathrm{mg} / 1$, father $1345 \mathrm{mg} / \mathrm{l}$ ); thus further supporting the codominant (double-dose) inheritance.

It was surprising how many children in the first year of life presented with highly elevated lipoprotein(a) concentrations, levels of above $1 \mathrm{~g} / \mathrm{l}$ being found. The scatter of results is reflected in tables 1 and 2 , and figure $3 b$. This is applicable to all age groups.

\section{Adults}

Although the results in figure 2 are from non-selected hospitalised patients, a comparison was made with the women who were only in hospital to give birth. The comparison between hospitalised patients of both sexes between 17 and 35 years and mothers of the same age can be seen in table 1. Figure $3 \mathrm{c}$ shows the individual results from 252 adults.

\section{Tabular and graphical data for all groups}

Table 1 summarises the distribution of lipoprotein(a) concentrations for each age group, in terms of the range and relevant percentiles. Where sufficient data are available, the groups have also been analysed according to sex. There was no statistically significant difference in lipoprotein(a) concentrations between the sexes in newborns and children up to 16 years of age. In the adult group (17-88 years) the median lipoprotein(a) concentrations were significantly higher in males $(p<0.05)$.

Table 2 shows the skewed distribution of the data for each group and the proportion of subjects in each group with lipoprotein(a) values above defined limits. Only relevant values have been included.

Figures $3 a-3 c$ show the individual values of all subjects included in the study. The median values of the data from figures $3 a-3 c$ are shown in figure 2 .

\section{Discussion}

The aim of the study was to try to establish reference ranges for lipoprotein(a) for newborns and children. From the results obtained, it can be stated that lipoprotein(a) reference range values can be defined for newborns, infants up to 6 months and children from 6 months to 16 years. The data presented here would support the use of an age-dependent recommended upper limit for lipoprotein(a) concentrations in serum. From the data in table 2, suggested warning limits are above 


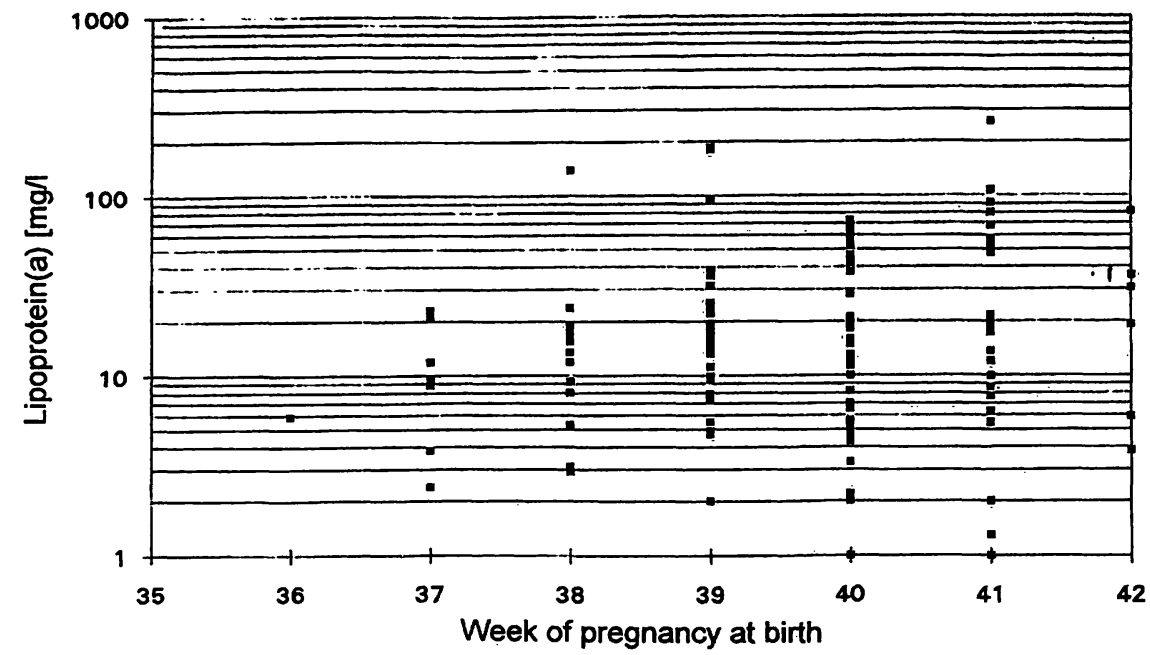

Fig. 3a Scatter of results from the 123 newborns in serum obtained from cord blood. The median values of these results from the left part of figure 2 . The abscissa shows the pregnancy week in which the child was born, the ordinate the respective lipoprotein(a) concentrations. The ordinate is logarithmic.

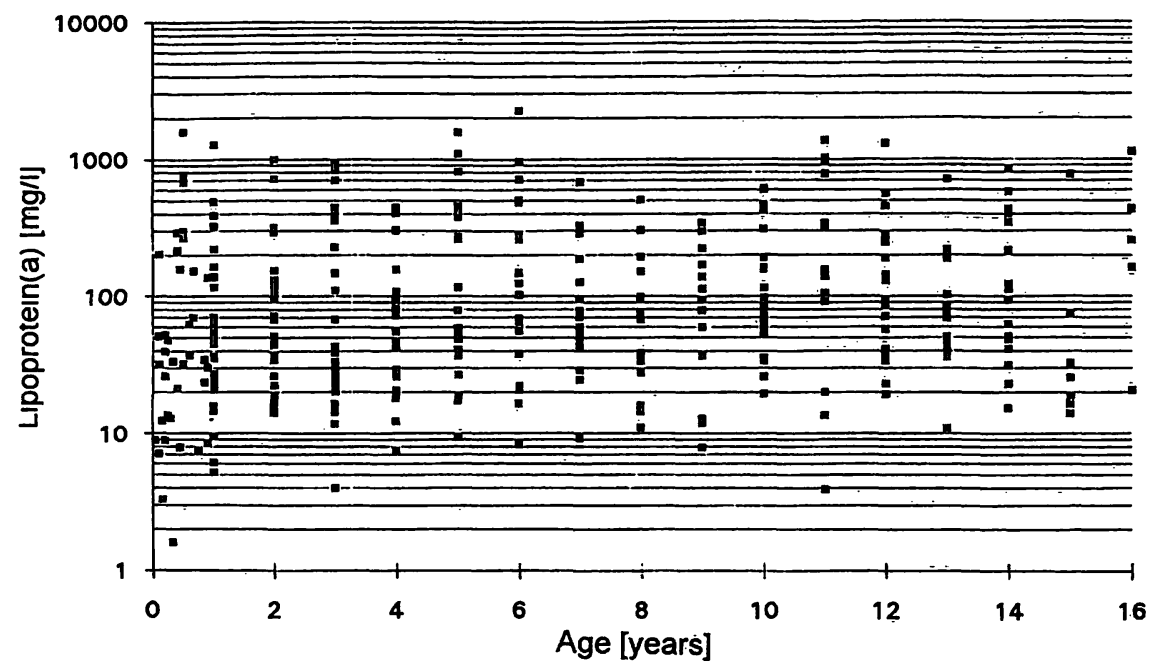

Fig. 3b Scatter of results from the 331 children. The abscissa shows the age of the children. Values under 1 year are entered as decimal age, above 1 year as integral age. The ordinate is as in

figure 3a. The median values of the grouped data form the middle part of figure 2.

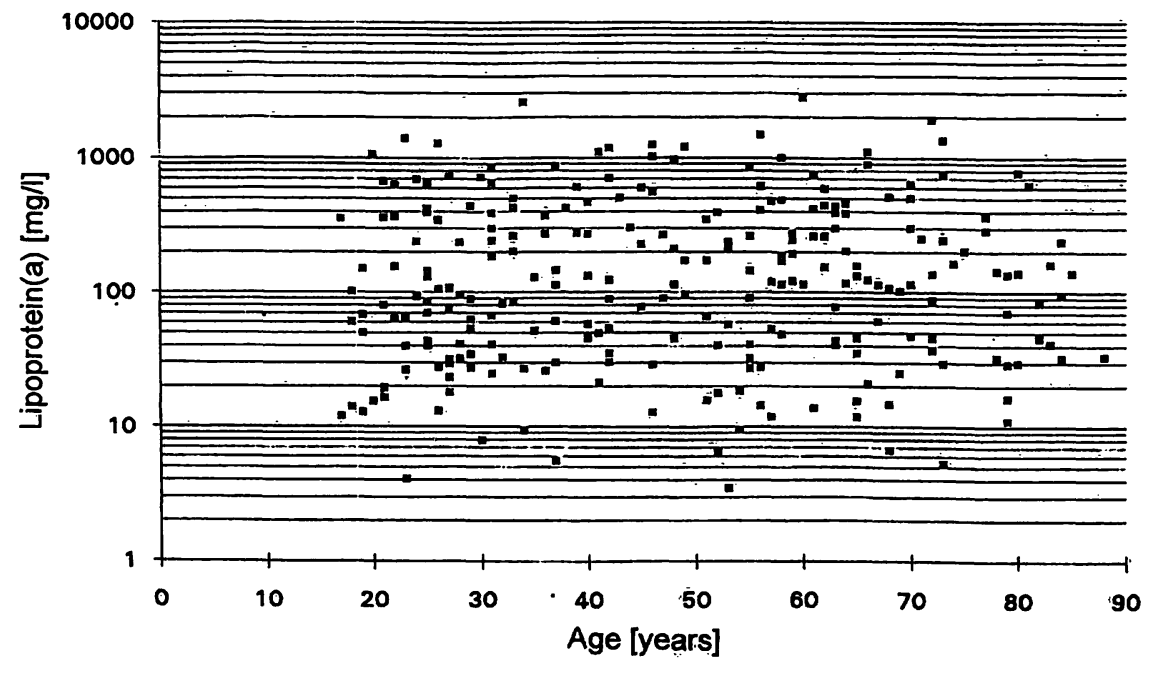

Fig. 3c Scatter of results in the 252 adults. The abscissa shows integral age, the ordinate the individual lipoprotein(a) concentra- tion. The median values of the grouped data are shown in the right hand part of figure 2 . $\rightarrow$ 
Tab. 1 Distribution of lipoprotein(a) values in different age groups.

\begin{tabular}{|c|c|c|c|c|c|c|c|c|}
\hline \multirow[t]{2}{*}{ Group } & \multicolumn{7}{|c|}{ Percentiles (mg/l) } & \multirow[t]{2}{*}{ Range } \\
\hline & 0.5 & 2.5 & 16 & 50 & 84 & 97.5 & 99.5 & \\
\hline \multicolumn{9}{|l|}{ Newborns } \\
\hline Male & $*$ & $<1$ & 4.1 & 13.1 & 55.6 & 255 & $*$ & $<1-339$ \\
\hline Female & $*$ & 1.0 & 3.8 & 14.2 & 55.0 & 122 & $*$ & $<1-102$ \\
\hline All & $<1$ & 1.0 & 4.0 & 13.9 & 55.4 & 204 & 286 & $<1-339$ \\
\hline \multicolumn{9}{|l|}{ Children $0.1-16 a$} \\
\hline Male & 1.6 & 6.1 & 23.3 & 69.2 & 382 & 1000 & 1200 & $1.0-2455$ \\
\hline Female & 3.7 & 7.9 & 14.9 & 67.8 & 360 & 1056 & 1340 & $5.0-1350$ \\
\hline All & 1.6 & 7.4 & 19.5 & 69.1 & 368 & 1040 & 1340 & $1.0-2455$ \\
\hline \multicolumn{9}{|l|}{ Adults $17-88 a$} \\
\hline Male & 3.5 & 6.5 & 28.5 & 144 & 505 & 1215 & 2688 & $3.5-2800$ \\
\hline Female & 5.0 & 7.2 & 26.4 & 89.0 & 469 & 1236 & 1442 & $4.1-1487$ \\
\hline All & 3.5 & 6.8 & 27.0 & 115 & 492 & 1220 & 2125 & $3.5-2800$ \\
\hline Mothers 17-35a & 4.1 & 5.8 & 18.5 & 92.5 & 502 & 1170 & 1390 & $4.1-1400$ \\
\hline Others $17-35 a$ & * & 9.4 & 19.6 & 104 & 423 & 1300 & $*$ & $7.8-2576$ \\
\hline
\end{tabular}

The groups comprised 123 newborns, 331 children, 252 adults, 80 mothers and 51 age-matched others. The asterisks denote that the groups were too small for these values to have any statistical mean-

Tab. 2 Distribution of lipoprotein(a) values in the different groups.

\begin{tabular}{llll}
\hline & \multicolumn{3}{l}{ Relationship Mean/median } \\
\cline { 2 - 4 } & Newborns & Children & Adults \\
\hline Male & 2.36 & 2.61 & 2.14 \\
Female & 1.84 & 2.90 & 2.35 \\
All & 2.07 & 2.71 & 2.72 \\
& & & \\
Lipoprotein(a) & Percentage of values & \\
(mg/) & & & \\
\hline$>25$ & & & \\
$>50$ & 27.7 & & \\
$>75$ & 17.7 & & \\
$>100$ & 8.5 & & \\
$>150$ & 6.8 & & \\
$>200$ & 5.3 & $31.1 / 27.5 *$ & \\
$>250$ & 3.0 & $26.7 / 25.0$ & $44.5 / 33.1$ \\
$>300$ & 1.5 & $23.0 / 23.8$ & $38.2 / 28.2$ \\
& 0.75 & $20.0 / 17.5$ & $27.2 / 27.5$ \\
\hline
\end{tabular}

* The separated values in the lower part of the table are male/female.

$25 \mathrm{mg} / \mathrm{l}$ for newborns in cord blood or serum, above 150 $\mathrm{mg} / \mathrm{l}$ for children, above $200 \mathrm{mg} / 1$ adolescents and above $300 \mathrm{mg} / 1$ for adults when the 75th percentile value is taken as in the Framingham second generation study (19). A sliding scale would be more applicable in terms of the results in figure 2 ; as the median values increase continuously from birth to the end of the sixth decade of life. These values can only be taken as a guide, as the number of observations is too small for setting limits. ing. There was no significant difference between the sexes, except for the adults, where males had higher values than females $(\mathrm{p}<0.05)$.

The results are interesting inasmuch as they show that high lipoprotein(a) concentrations are observable within the first months of life. Of the children admitted to hospital within the first year of life, $20 \%$ (10/50) showed lipoprotein(a) values above $200 \mathrm{mg} / \mathrm{l}$. Lipoprotein(a) levels appear to reach maximal levels at the end of the sixth decade of life, although a two-fold rise in lipoprotein(a) values during the first 8 days after birth was seen in 9/20 newborns, whose blood was taken for other tests. The general claim that lipoprotein(a) levels increase over the first 8 days of life (9) due to the maturation of lipoprotein(a) gene expression within this time (8) is not supported by the present study. The claim that lipoprotein(a) concentrations at 8 months were similar to those seen in adults $(8,9)$ could not be confirmed in the present study. In the limited number of children studied over the first 9 days of life the only observation made was that in $9 / 10$ children with a cord serum lipoprotein(a) value over $25 \mathrm{mg} / \mathrm{l}$, this value rose over the observation period by a factor of $2-3$, the 10th child having a value which remained constant around $27 \mu \mathrm{g} / \mathrm{l}$. No such incresae was observed in 10 children with lipoprotein(a) values at birth under $20 \mathrm{mg} / \mathrm{l}$. These findings indicate that newborns with a lipoprotein(a) concentration above $25 \mathrm{mg} / \mathrm{l}$ should be checked again at around 6 months of age.

For ethical reasons, it was not possible to include a group of non-hospitalised healthy children for comparison. The fact that the children were admitted to the hospital without known lipid disorders would support the 
theory that the results presented here reflect the situation in the general population. This is borne out further by comparison of the values of the mothers with those from both men and women of the same age, who were hospitalised.

It has been reported that apolipoprotein B synthesis at birth is only $30 \%$ of that found in adults, and the synthesis of this apolipoprotein reaches adult levels after 7 days (9). The low concentrations of lipoprotein(a) reported here are not, however, due to a low synthesis of apolipoprotein(a). The assay used in the present study employed two antibodies directed against apolipoprotein(a), i.e. the sandwich partner was not directed against apolipoprotein $\mathrm{B}$, although such an assay has been published from this laboratory (15). Other authors (9) have shown that the synthesis of apolipoprotein(a) first reaches maturity after about 180 days. The present results show that the range of values seen at about 6 months is similar to that in adults, although the median value is lower (fig. 3a).

An interesting observation was that the median lipoprotein(a) values in males decreased after the completion of the 6th decade of life. This is not due to decreased synthesis, but due to the death of those with high lipoprotein(a) from atherosclerotic and cardiovascular disease. All patients older than 70 and with grossly elevated lipoprotein(a) (over $1 \mathrm{~g} / \mathrm{l}$ ) were women. The spread of results, as seen in table 1 , shows that the concentrations of lipoprotein(a), as well as being log-nor-

\section{References}

1. Bruppacher, R. \& Ritzel, G. (1975) Ernährungsgewohnheiten und Blutfettspiegel bei Adoleszenten. Sozial Präventivmed. 20, $222-221$.

2. Srinivasan, S. R., Frerichs, R. R., Webber, L. S. \& Berenson, G. S. (1976) Serum lipoprotein profile in children from a biracial community. Circulation 54, 309-318.

3. Frerichs, R. R., Srinivasan, S. R., Webber, L. S. \& Berenson, G. S. (1976) Serum cholesterol and triglyceride levels in 3,446 children from a biracial community. Circulation 54, 302-309.

4. Andersen, G. E., Lous, P. \& Frijs-Hansen, P. (1979) Screening for hyperlipoproteinaemia in 10,000 Danish newborns. Acta Paediatr. Scand. 68, 541-545.

5. Morrison, J. A., Larsen, R., Geatfelter, L., Boggs, D., Burton, K., Smith, C., Kelly, K., Mellies, M. J., Khoury, P. \& Glueck, C. J. (1980) Nutrient intake: relationship with lipids and lipoproteins in 6-19 year old children: The Princeton School District Study. Metabolism 29, 133-140.

6. Boulton, T. J. C. (1980) Serum cholesterol in early childhood. Acta Paediatr. Scand. 69, 441-445.

7. Wang, X. L., Wilcken, D. E. \& Dudman, N. P. (1990) Neonatal apo A-I, apo B and apo(a) levels in dried blood spots in an Australian population. Pediatr. Res. 28, 496-501.

8. Wilcken, D. E., Wang, X. L. and Dudman, P. (1992) The apo $A, B$, a of coronary risk: Back to kindergarten. Aust. N.Z.J. Med. 22 (5 Suppl.), 570-575. mally distributed, have a similar distribution (mean/median) throughout life.

The logarithmic distribution of results can be seen clearly from all figures, yet many research groups still give concentrations in terms of mean and standard deviation, although this has been rightly criticised as reducing the value of such publications (20).

The most striking findings were that the lipoprotein(a) median concentrations follow the "stress-curve" of life, peaking exactly during the 15 years where the most myocardial infarction cases occur. One must postulate that although lipoprotein(a) disposition is genetically determined, lipoprotein(a), like the other lipid "risk factors" is affected by the stress of daily life. This point must be taken into account when advising the parents of children and adolescents to adopt a life style where stress is kept to a minimum. A dietary education programme for children with elevated cholesterol levels has already been published and is based on both dietary, as well as "hands-on" therapy (21).

Current concepts must be changed as new facts concerning lipoprotein(a) come to light, especially if the hypothesis that the size of the lipoprotein(a) molecule influences its atherosclerotic effects proves to be correct.

Finally, it must be stated that the results here are from defined groups of subjects of Caucasian origin, and in the light of other studies on lipid analytes (22-24) may not be transferable to other ethnic groups or to mixed populations, although studies on black and white newborns (11) have shown no difference in lipoprotein(a) concentrations at birth between the two races.

9. Van Biervliet, J. P., Labeur, B., Michiels, G., Usher, D. C. \& Rosseneu, M. (1991) Lipoprotein(a) profiles and evolution in newborns. Atherosclerosis 86, 173-181.

10. Van Biervliet, J. P., Michiels, G. \& Rosseneu, M. (1991) Quantification of lipoprotein(a) in dried blood spots and screening for above-normal lipoprotein(a) concentrations in newborn. Clin. Chem. 37, 706-708.

11. Rifai, N., Heiss, G. \& Doetsch, K. (1992) Lipoprotein(a) at birth in blacks and whites. Atherosclerosis 92, 123-129.

12. Panteghini, M., M. \& Pagani, F. (1991) Serum concentrations of lipoprotein(a) during normal pregnancy and postpartum. Clin. Chem. 37, 2009-2010.

13. Zechner, R., Desoye, G., Schweditsch, M. O., Pfeiffer, K. P. \& Kostner, G. M. (1986) Fluctuations of plasma lipoprotein A concentrations during pregnancy and post partum. Metabolism 35, 333-336.

14. Cremer, P., Nagel, D., Labrot, B., Muche, R., Elster, H., Manin, H., Seidel, D. (1991) Göttinger Risiko-, Inzidenz- und Prävalenzstudie (GRIPS), Springer, Berlin, Heidelberg, pp. 72-73.

15. Keßler, A., Schumacher, M. \& Wood, W. G. (1994) Immunoluminometric assays for the quantification of apolipoproteins AI, B, C-II, (a) and lipoprotein(a). Eur. J. Clin. Chem. Clin. Biochem. 32, 127-135.

16. Kallio, M. J., Salmenpera, L., Siimes, M. A., Perheentupa, Ji. \& Miettinen, T. A. (1993) Tracking of serum cholesterol and 
lipoprotein levels from the first year of life. Paediatrics 91, 949-954.

17. Wade, D. P. (1993) Lipoprotein(a). Curr. Opin. Lipidol. 4, 244-249.

18. Boomsma, D. I., Kaptein, A., Kempen, H. J., Gevers-Leuven, J. A. \& Princen, H. M. (1993) Lipoprotein(a): Relation to other risk factors and genetic heritability. Results from a Dutch parent-twin study. Atherosclerosis 99, 23-33.

19. Schaefer, E. J., Genest, J. J. Jr., Ordovas, J. M., Salem, D. N. \& Wilson, P. W. F. (1993) Familial lipoprotein disorders and premature coronary heart disease. Curr. Opin. Lipidol. 4, $288-298$.

20. Bhatnagar, D. \& Durrington, P. N. (1993) Does measurement of apolipoproteins add to the clinical diagnosis and management of dyslipidaemia? Curr. Opin. Lipidol. 4, 299-304.

21. Shannon, B., Greene, G., Stallings, V., Achterberg, C., Berman, M. K., Gregoire, J., Marecic, M. \& Shallcross, L. (1991) A dietary education program for hypercholesterolemic children and their parents. J. Am. Diet. Assoc. 91, 208-212.
22. Srinivasan, S. R., Wattigney, W., Webber, L. S. \& Berenson, G. S. (1989) Relation of cholesterol to apolipoprotein B in low density lipoprotein of children. The Bogalusa Heart Study. Arteriosclerosis 9, 493-500.

23. Ragoobirsingh, D. \& Davidson, J. B. (1990) The effect of demographic factors on serum lipids in diabetics of Trinidad and Tobago. Possible association with ischaemic heart disease. West Indian Med. J. 38, 99-104.

24. Donohue, R. P., Jacobs, D. R. Jr., Sidney, S., Wagenknecht, L. E., Albers, J. J. \& Hulley, S. R. (1989) Distribution of lipoproteins and apolipoproteins in young adults - The CARDIA Study. Arteriosclerosis 9, 656-664.

Prof. W. G. Wood

Institut für Klininische

Laboratoriumsdiagnostik

Klinikum der Hansestadt Stralsund

Krankenhaus Am Sund

Postfach 103

D-18402 Stralsund

Germany 
